\title{
Climate-change adaptation on rangelands: linking regional exposure with diverse adaptive capacity
}

\author{
David D Briske $^{1 *}$, Linda A Joyce ${ }^{2}, \mathrm{H}$ Wayne Polley ${ }^{3}$, Joel R Brown ${ }^{4}$, Klaus Wolter $^{5}$, Jack A Morgan ${ }^{6}$, \\ Bruce A McCarl ${ }^{7}$, and Derek W Bailey ${ }^{8}$
}

\begin{abstract}
The ecological consequences of climate change are predicted to vary greatly throughout US rangelands. Projections show warming and drying in the southern Great Plains and the Southwest, warmer and drier summers with reduced winter snowpack in the Northwest, and warmer and wetter conditions in the northern Great Plains. Primarily through their combined effects on soil water availability, these climatic changes will modify plant production and community composition, which will, in turn, affect the livelihoods of humans who rely upon livestock grazing. The ability of rangeland managers to assess risk and prepare for climate change varies greatly and reflects their different adaptive capacities. Geographically specific exposure to climate change and a diverse adaptive capacity to counteract these changes will require development of varied adaptation strategies that can accommodate the various needs and abilities of livestock managers.
\end{abstract}

$I^{\mathrm{n}}$ ncreasing atmospheric greenhouse-gas (GHG) concentrations have elevated global temperature by $1^{\circ} \mathrm{C}$ since industrialization (ca 1750) and are anticipated to result in an additional $1{ }^{\circ} \mathrm{C}$ rise by mid-century, regardless of projected rates of GHG emissions (NRC 2010; IPCC 2013). Warming will be accompanied by modified amounts and patterns of precipitation, and a greater frequency and intensity of extreme weather events. At the ecosystem scale, the indirect effects of climate change - such as increased wildfire incidence and modified distributions and densities of native and invasive species, including insects and disease-causing organisms - and the direct

\section{In a nutshell:}

- Climate change will affect millions of people whose livelihoods are linked to livestock grazing on US rangelands

- Livestock grazing will be directly influenced by changes in the amount, nutrient content, and seasonal availability of plant production, as well as by the adverse effects of heat, water limitation, and pathogen loads on animal performance

- Geographically specific ecological consequences and diverse adaptive capacity among managers represent underappreciated and interacting components of climate-change adaptation

- Adaptation planning must recognize and accommodate both geographic specificity and varied adaptive capacity to promote effective climate-change adaptation

${ }^{1}$ Department of Ecosystem Science and Management, Texas AEM University, College Station, TX *(dbriske@tamu.edu); ${ }^{2}$ Human Dimensions Research Program, US Department of Agriculture Forest Service, Rocky Mountain Research Station, Fort Collins, CO; ${ }^{3}$ US Department of Agriculture-Agricultural Research Service, Grassland, Soil and Water Research Laboratory, Temple, TX; continued on p 256 effects of climate change are anticipated to be similar in magnitude (NRC 2010). Collectively, the consequences of climate change, interacting with large-scale shifts in human land use, will likely modify ecosystem processes and the livelihoods that they support (Polley et al. 2013).

Rangelands comprise approximately $30-40 \%$ of global terrestrial area and deliver diverse ecosystem services; this land's predominant use, livestock grazing, contributes to the livelihoods of millions of humans (Sayre et al. 2013). These livelihoods are vulnerable to climate change from both an ecological and a socioeconomic perspective (Reynolds et al. 2007). Rangelands represent ecologically diverse arid and semiarid systems characterized by low plant productivity and high precipitation variability, including frequent drought. Rangeland managers often have limited financial and social capital, modest infrastructure, and few options to diversify livelihoods beyond livestock grazing, and are isolated from major urban centers and governing institutions (Sayre et al. 2013). The vulnerability of rangeland-based livelihoods to climate change provides a strong justification for the acceleration of planning and implementation of adaptation strategies.

Climate change is projected to have geographically diverse consequences on US rangelands (Polley et al. 2013). Consequently, geographically specific adaptation strategies will be required to contend with localized challenges and opportunities. The heterogeneity among individuals and groups - both within and among geographic regions regarding the recognition, capacity, and motivation to implement various adaptation strategies represents a second critical component of climate-change adaptation (Williamson et al. 2012; Joyce et al. 2013). We contend that the interaction between the geographic specificity of climate change and the heterogeneity in the adaptive capacity 


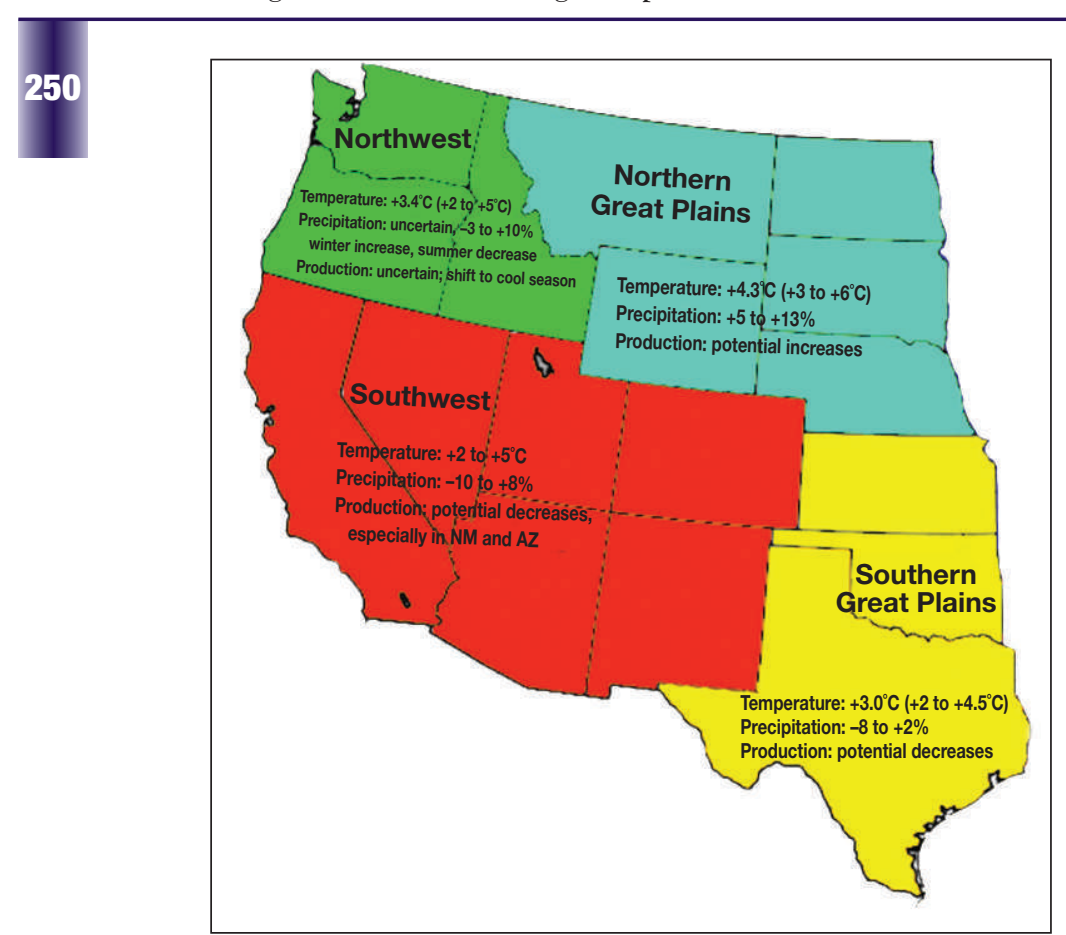

Figure 1. Climate-change projections for US rangelands illustrating the unique exposures to and potential consequences for livestock production in four geographic regions. Projections were generated from recent simulations of CMIP5 (courtesy of J Eischeid) and data were obtained from Taylor et al. (2012) and Baker and Huang (2014). Regional designations follow those of USGCRP (2009), except that the Great Plains have been divided into two separate regions, the northern and southern Great Plains, to emphasize the large differences in climate projections.

of managers - that is, their ability to respond to, create, and shape change in a system - represents an underappreciated barrier to the development and implementation of adaptation strategies. Thus, public programs, strategies, and incentives to implement climate-adaptation measures will be far more effective if they are tailored to select categories of individuals or social groups that are experiencing geographically specific climatic consequences. The objectives of this paper are to: (1) review the geographic specificity of climate change in four regions of the western US, (2) identify essential components of adaptive capacity that are relevant to rangeland managers, (3) evaluate acknowledged adaptation strategies and barriers to their implementation, and (4) highlight the geographic specificity of climate change and heterogeneous adaptive capacity among managers as interacting components of adaptation planning and implementation. Although we focus on rangelands, this conceptual framework could be applicable to other natural-resource systems, including agriculture and forestry.

\section{Subcontinental climate projections and consequences}

The ecological consequences of climate change are anticipated to vary greatly among geographic regions based upon current environmental conditions and unique interactions among climate-change drivers (Figure 1; Polley et al. 2013). Ecosystem processes and the services that they provide will be modified by climate change and its primary drivers - elevated atmospheric carbon dioxide $\left(\mathrm{CO}_{2}\right)$ concentrations, warming, and modified precipitation regimes - on soil water availability (Knapp et al. 2008). Consensus projections from climate-change models for the middle of the 21st century indicate that the US southern Great Plains, the US Southwest, and northern Mexico will become warmer and drier, while the US Northwest will become warmer and drier during summer and will experience reduced snowpack in winter; at the same time, the US northern Great Plains and southern Canada will become warmer and wetter, especially during the winter (Meehl et al. 2007; IPCC 2013). These projections are only approximations because reliable estimates of future climates, especially for precipitation, are not yet possible at regional scales (IPCC 2013). For example, results from the recent Coupled Model Intercomparison Project Phase 5 (CMIP5) are consistent with previous temperature projections for the southwestern US (Taylor et al. 2012; Baker and Huang 2014; J Eischeid pers comm) but forecasted less variance for annual rainfall than previous simulations. Nevertheless, vulnerability assessments and adaptation strategies must recognize and address geographically specific exposures to effectively offset climate-change impacts (Joyce et al. 2013).

\section{Southwest}

In this region, warming and reduced precipitation will synergistically decrease soil water availability, thereby diminishing both the amount and nutrient content of plant production and altering plant community composition (Figure 1; Polley et al. 2013). Declines in water availability decrease plant growth and shorten the growing season, thus reducing available livestock forage. Collectively, changes in precipitation and temperature regimes may alter plant species composition and plant phenology to modify the seasonal availability of high-quality forage (Walther 2003; Craine et al. 2009). The digestibility and nutritive value of plant tissues are diminished by the higher carbon-to-nitrogen (C:N) ratio that accompanies plant growth under elevated atmospheric $\mathrm{CO}_{2}$ conditions, and by the accelerated leaf senescence induced by water stress (Morgan et al. 2004). Reduced nutrient intake, higher temperatures, and more frequent heat stress are likely to further reduce livestock production and adversely affect people whose livelihoods are dependent on it (CCSP 2008; Howden et al. 2008). More frequent and severe droughts are anticipated to modify plant species composition and cover directly by contributing to episodic plant die-offs and indirectly through increasing the frequency of fire events. In the Mojave Desert and Great Basin over the past 20 years, increased fire frequency has converted some desert shrublands and shrub steppe communities to annual grasslands (CCSP 2008; Balch et al. 2013). 


\section{Southern Great Plains}

Warming and drying, especially in Texas, are anticipated to reduce both plant production and nutritive content in ways similar to those described for the Southwest. These climatic changes are likely to negatively affect livelihoods by reducing stocking rates and total livestock production, and potentially by increasing production costs associated with the purchase of supplemental feed (Figure 1; Polley et al. 2013). Warmer temperatures may improve winter survival and increase abundance of ectoparasites, including lone star ticks (Amblyomma americanum) and horn flies (Haematobia irritans), that will further suppress livestock performance. Warming and drying are expected to modify vegetation composition and land-surface cover, including an increase in the density and cover of woody plants. Growth of both eastern redcedar (Juniperus virginiana) and post oak (Quercus stellata) were reduced by experimental intensification of summer drought conditions, but growth of eastern redcedar increased in response to warming, while that of post oak did not (Volder et al. 2013). This suggests that encroachment by Juniperus spp is likely to accelerate with continued climate change and will further reduce the extent and production of grasslands. Woodland encroachment has already forced the reassessment of fire regimes and implementation of prescribed-burning programs within this region (Twidwell et al. 2013).

\section{Northern Great Plains}

Warming and increased precipitation, coupled with elevated atmospheric $\mathrm{CO}_{2}$ concentrations, are expected to increase plant production by alleviating temperature and water limitations on plant growth and extending the growing season (Figure 1; Polley et al. 2013). Such an outcome would presumably improve the efficiency of livestock production by reducing the period of winter feeding and allowing for increased stocking rates (CCSP 2008). However, it is uncertain to what extent elevated atmospheric $\mathrm{CO}_{2}$ will reduce forage quality, and thus livestock production and profitability, by increasing plant C:N ratios. Nitrogen concentrations of live plant tissues less than $1.5 \%$ are likely to reduce animal growth and reproduction, while values of approximately $1 \%$ will be sufficient to meet maintenance requirements of mature animals. The adverse effects of low nutritive forage can be offset by dietary $\mathrm{N}$ supplements, but this will increase both operating costs and labor requirements (Schauer et al. 2005).

In addition, these climatic shifts are projected to modify plant community composition by facilitating recruitment and growth of invasive herbaceous plants - including leafy spurge (Euphorbia esula) and diffuse knapweed (Centaurea diffusa), as well as several species of sub-shrubs - and alter the distributional ranges of other invasive species (Morgan et al. 2007). Spotted knapweed (Centaurea biebersteinii) may shift toward higher elevations, while leafy spurge may extend its range northward into southern Canada (Bradley

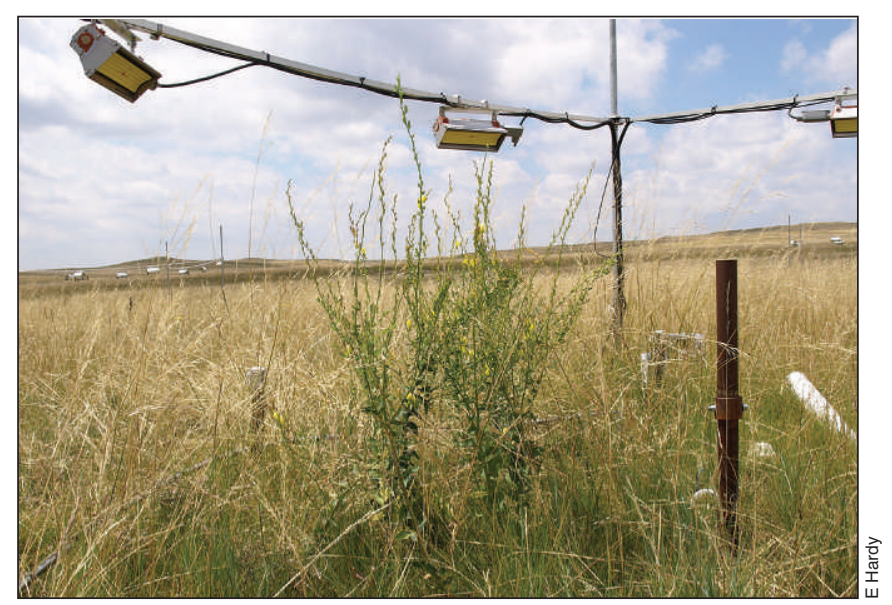

Figure 2. Elevated $\mathrm{CO}_{2}$ promotes the invasion of Wyoming mixed-grass prairie by Dalmatian toadflax (Linaria dalmatica), whereas warming has little effect.

and Wilcove 2009). We anticipate that increased abundance and expanded ranges of exotic invasive species are more likely to adversely affect livestock production than such changes in native species, because exotics are often unpalatable and occasionally toxic to livestock (Figure 2).

\section{Northwest}

Warming is projected to decrease soil water availability, especially during late summer, and to reduce plant production in this region (Figure 1; Polley et al. 2013). Earlier snowmelt, which now occurs 10-15 days earlier than it did 50 years ago, and reduced stream flow are expected to reduce primary production and modify plant species composition in riparian systems (CCSP 2008). Benefits to livestock production provided by milder, wetter winters may partially offset the negative effects of longer and drier summers, but supplemental feeding may be required if the summer dry period is prolonged. Warming and associated range expansion of invasive annual grasses are likely to produce larger and more frequent fires that function as amplifying feedbacks, promoting further invasion of the exotic annual grasses cheatgrass (Bromus tectorum), medusahead (Taeniatherum caput-medusae), and red brome (Bromus madritensis rubens), especially at higher elevations and in northern portions of their current ranges (Smith et al. 2000; Ziska et al. 2005). Yellow starthistle (Centaurea solstitialis) is expected to become more prolific but to expand its range only marginally (Bradley and Wilcove 2009). The lower palatability and nutrient content of these invasive species will negatively affect livestock production by reducing forage intake and increasing foraging time of livestock (Polley et al. 2013).

\section{Adaptive capacity}

Rangeland managers have historically developed considerable adaptive capacity to contend with economic, environmental, and ecosystem variability. However, climate 
Panel 1. An assessment of heterogeneous adaptive capacity among 100 rangeland livestock managers

Adaptive capacity is necessary to convert natural and social resources into useful adaptation strategies, and is considered to include four dimensions: capacity to manage risk and uncertainty; capacity to plan, learn, and reorganize; emotional and financial flexibility to incorporate the costs of change; and interest in adapting to change.

These four dimensions were used to assess the adaptive capacity of 100 livestock managers in northern Australia to address climatic variability (Figure 3; Marshall and Smajgl 20I3). In face-to-face interviews, managers were asked a series of questions and were then categorized as possessing low or high capacity for each of the four dimensions. The skill sets of individual managers could include high capacity in all, some, or none of the four dimensions. Variation in adaptive capacity of the 100 managers represented all 16 combinations of the four dimen-

sions. Managers perceived their ability to address climate risk positively; for example, Marshall and Smajgl (2013) noted that $90 \%$ of managers believed that they were "more likely to survive drought compared to other cattle producers". With respect to capacity to plan, managers appeared to develop plans for risks such as drought based on their own skills and knowledge. Responses varied from "just hope for the best if there is a drought" (21\%) to they were "good at doing what [they] do and trust [their] own decision" (90\%). Their emotional flexibility was generally greater than their financial flexibility. The managers expressed an interest in climatechange adaptation but no interest in the strategies. While $83 \%$ were interested in how they could better prepare for drought, less than $60 \%$ were prepared to learn new skills outside of the industry or attend a workshop on how to better manage for drought. Any single initiative to address adaptation to climate change is unlikely to meet the needs of all managers. For instance, some managers could benefit by improving their ability to manage risk, whereas others would benefit more by developing other skills and information networks.

change is projected to increase the frequency and extremes of climatic fluctuations beyond those previously experienced, which will require even greater adaptive capacity to minimize failure and abandonment of production enterprises. Adaptive capacity - which encompasses the ability to recognize and manage risk, plan and implement adaptation strategies, display financial and emotional flexibility (described in the section below), and even exhibit awareness of climate change and the need for adaptation - has been demonstrated to vary greatly among managers (Panel 1 and Figure 3; Marshall and Smajgl 2013). We reference the Australian survey conducted by Marshall and Smajgl (2013) because it is the most comprehensive assessment of heterogeneous adaptive capacity among livestock managers. The attributes discussed in that survey are often used to characterize adaptive capacity, and thus we consider the survey results to be broadly applicable to US rangelands and rangeland managers as well. The adaptive capacity of managers, and consequently of livestock operations, will establish the foundation upon which adaptation strategies for climate change are conceptualized, evaluated, and implemented (Fazey et al. 2010). Yet many important regional adaptations will far exceed the financial and technical capacity of individual operations and may require public investment (Mendelsohn 2000; IPCC 2014).

\section{Risk management}

Managing risks associated with change and uncertainty is fundamental to adaptive capacity and adaptation (Marshall and Stokes 2014). Rangeland livestock managers are continually confronted by risks associated with the unpredictability of markets and weather (Torell et al. 2010). Drought management planning can help ranchers minimize reactionary approaches to drought that may result in a loss of productivity and financial assets. Evidence of heterogeneous adaptive capacity is seen in the implementation of current drought management planning. For example, of Utah cattle ranchers surveyed after the 1999 to 2004 drought, only $14 \%$ were self-described as adequately prepared. However, drought preparedness increased to $29 \%$ of ranchers in 2009, but most remained ill-prepared (Coppock 2011). Sixty percent of Wyoming ranchers incorporated some type of drought management planning, and multiple adaptation strategies were adopted with increasing duration of drought (Kachergis et al. 2013). Similarly, nearly 50\% of the ranchers surveyed in Australia were unprepared to manage risk and uncertainty associated with periodic drought (Panel 1; Marshall and Smajgl 2013). 


\section{Planning and learning for enterprise reorganization}

The capacity to plan, learn, and reorganize enterprise structure is dependent upon creativity, experiential and scientific knowledge, awareness of opportunities, and the skill to capitalize on those opportunities (Stafford Smith et al. 2007; Joyce et al. 2013; Marshall and Stokes 2014). Livestock managers recognize that social capital, in the form of learning networks and environmental awareness, is a more important component of climate-change adaptation than technical information and solutions (Marshall 2010). Ranchers who exhibit foresight and have access to conservation information are most likely to participate in conservation programs (Lubell et al. 2013). Consequently, livestock managers will require a variety of adaptation strategies to accommodate the heterogeneous adaptive capacity within this agricultural sector (Panel 1 and Figure 3; Marshall and Smajgl 2013).

Production efficiencies, market pressures, and climate change have led to the restructuring and physical relocation of livestock production systems in parts of the US (Joyce et al. 2013; Mu et al. 2013). Managers in the hotter areas of Texas, for instance, have increased the proportion of Brahman and Brangus (crosses between Brahman and Angus breeds) cattle in their herds (Zhang et al. 2013). This strategy of crossing the two cattle breeds combines consumer preference for Angus beef with the heat and insect tolerance of Brahmans, an adaptation that may become more widely implemented as projections of a warmer and drier climate are realized in Texas and the Southwest US (Hoffmann 2010; Mu et al. 2013).

\section{Emotional and financial flexibility}

Emotional and financial flexibility of livestock managers are strong indicators of their ability to cope with change. Managers with limited social and natural-resource flexibility are especially vulnerable to weather variation (Marshall 2011) and potentially to climate change. Limited emotional flexibility is indicative of a strong attachment to livestock production as a livelihood and a reluctance to search for employment elsewhere or to diversify livelihoods (Marshall and Smajgl 2013). Often, these managers are older, are highly independent, and lack transferable skills. Financial flexibility, as indicated by income and size of production enterprises, has been shown to influence the acceptance and implementation of innovative adaptations. Managers with larger properties are more likely to implement a greater number of drought management adaptations to increase enterprise flexibility and lessen the adverse consequences of drought (Kachergis et al. 2013).

\section{Climate-change awareness}

Managers' perceptions of climate change will affect their willingness to develop and adopt various adaptations. Suboptimal investments in adaptive capacity, known as "adaptation deficits", have been associated with insufficient awareness of climate-change issues, climate-change denial, and distorted perceptions of risk and current preparedness (Williamson et al. 2012). Knowledge and perceptions of climate change were influenced by partisan affiliation, political ideology, and gender. Female managers were more likely to hold more scientifically accurate knowledge about climate change than their male counterparts, regardless of political affiliation (Liu et al. 2014).

\section{Adaptation strategies}

Many adaptation strategies specific to rangeland livestock production - involving conservative stocking rates, robust drought contingency planning, a shift in livestock breeds or species, management of invasive plants and animal parasites, modified operational structure, and geographic relocation of production enterprises - have been identified (Joyce et al. 2013). These strategies vary greatly in the extent of modification, timing of implementation, specificity of impact, potential for success, and, as noted previously, the likelihood of adoption as influenced by varying adaptive capacity among managers.

Drought contingency planning for livestock production systems includes low to moderate grazing intensities, maintaining reserve forage supplies, flexible management of herd size and composition, and procedures for timely destocking when necessary (Joyce et al. 2013). In areas of highly variable forage production, maintaining grazing flexibility by shifting from cow-calf enterprises to enterprises using yearling cattle may be critical for economic success; this degree of grazing flexibility, however, incurs additional costs and financial risks that may prove challenging for risk-averse managers (Torell et al. 2010). A switch to alternative livestock species represents another viable adaptation. As compared with cattle, smaller ruminant livestock - sheep and goats - are more heat tolerant, require less water, can consume a greater diversity of plant species, and may be better suited to future climates, especially in the southern regions (Polley et al. 2013). Nevertheless, the availability of market infrastructure and rancher perceptions about and abilities to manage smaller ruminant livestock may necessitate assistance with market development, as well as training and incentives for managers.

\section{Matching adaptation with adaptive capacity and geographic exposure}

The sensitivity of a region to climate change will be determined not only by ecological responses but also by the potential adaptive capacity of managers. For example, in the Southwest, the percentage of all agricultural enterprises with sales less than $\$ 10000$ is higher than in the northern Great Plains (NASS 2012a), implying that managers in the former region may have fewer resources to implement novel, and potentially expensive, adaptations. The percentage of principal enterprise managers 
who are $>65$ years of age is higher across the Southwest and southern Great Plains than in the northern Great Plains and the Northwest (NASS 2012b), suggesting that managers in the former regions may demonstrate greater attachment to place and less willingness to diversify or relocate enterprises. These social characteristics may indicate a lower adaptive capacity, leading to higher rates of enterprise failure. A large number of such failures could irreversibly modify the infrastructure of the regional livestock industry, if the size of regional livestock herds falls below a threshold of economic viability. Recent drought in the southern Great Plains and the consequential closure of cattle feedlots and beef processing plants in the region represent such a case, which will further constrain livestock marketing opportunities for the remaining managers (Johnston 2014).

Adaptations will be required to minimize climatechange impacts and to exploit opportunities associated with more favorable climatic conditions (Table 1). Adaptations to exploit opportunities in the northern Great Plains will involve development of facilities to support greater livestock numbers, and maintenance of sufficient marketing and pricing strategies. The percentage of agricultural enterprises that reported farming as their primary occupation is highest in the northern Great Plains, and average annual enterprise sales in the region are well above $\$ 10000$ (NASS 2012a, c). This suggests that sufficient financial capital is available for managers to capitalize on opportunities associated with greater livestock pro- duction, but information addressing enterprise expansion and marketing strategies may be required. Novel agricultural opportunities associated with climate change will likely result in competition for land, water, energy, and labor resources among crop and livestock production systems, which will require assessment of land-use trade-offs.

Current federal programs, such as the Environmental Quality Incentives Program (EQIP), offer technical assistance opportunities for various conservation measures to address local and regional environmental concerns (Reimer and Prokopy 2014). However, these programs do not contain a sufficient variety of options to account for the diverse adaptive capacity of managers. The interaction of heterogeneous adaptive capacity among managers and geographically specific ecological consequences of climate change will be particularly challenging for social organizations that offer assistance based on the "average" enterprise structure or "average" adaptive capacity of managers (Figure 4). Multiple approaches will be required to combine scientific and experiential knowledge, develop partnerships for co-production of new management-relevant knowledge, and incentivize the implementation of adaptation strategies that cater to the needs and abilities of diverse managers and associated stakeholder groups (Dilling and Lemos 2011; Bierbaum et al. 2013). Some of these strategies are currently in place, but others are required in the form of social organizations capable of providing risk-management programs and financing for technology and equipment to implement capital-intensive adaptations (IPCC 2014).

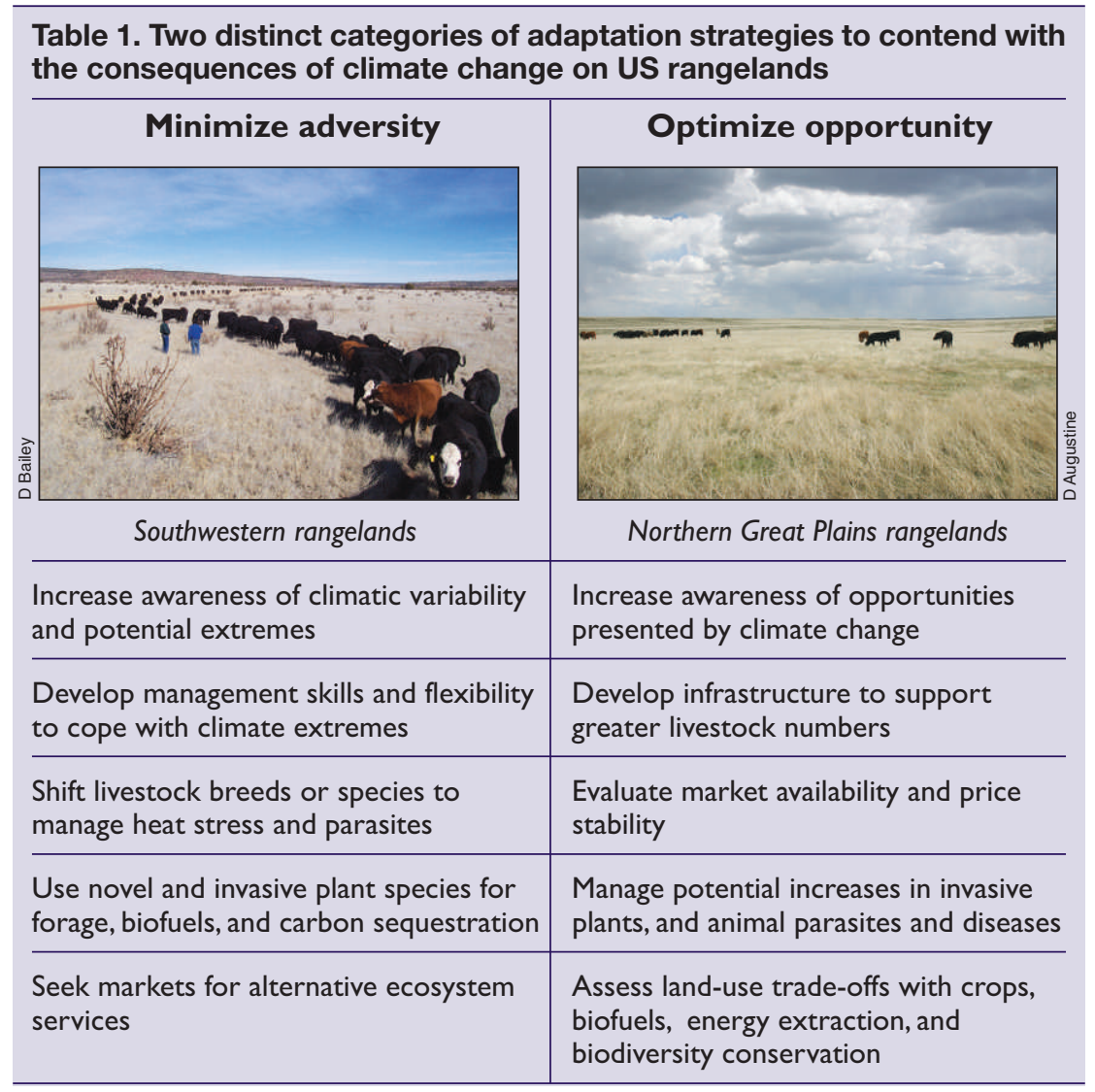

\section{When incremental adaptation fails}

Severity of exposure to climate change, enterprise sensitivity, and available adaptive capacity may interact in some instances to produce conditions where incremental adaptation is insufficient to sustain current livelihoods (Joyce et al. 2013). In these cases, production enterprises and even entire human-ecological systems may have to be reorganized to create alternative livelihoods based on different combinations of ecosystem services (Kates et al. 2012). For example, enterprise managers may find that it is not economical to compensate for climate-induced declines in livestock production resulting from more frequent and intense drought, accelerated woody plant encroachment, and invasion of exotic herbaceous species (Polley et al. 2013). Alternative livelihoods to livestock grazing, including ecotourism, watershed management, and alternative energy sources, may be more compatible with the ecological and social condi- 
tions of some regions in the future. Development of frameworks and policies that identify and guide implementation of transformational change is a critical but largely overlooked challenge.

\section{Conclusion}

Livelihoods linked to livestock grazing in the western US are especially vulnerable to climate change. Vulnerability is a function of exposure to unique intensities and combinations of climate-change drivers, along with the diverse adaptive capacity of managers to contend with these consequences. The geographic specificity of ecological consequences and the heterogeneous adaptive capacity among enterprise managers represent underappreciated and interacting components of climate-change adaptation. Categories of adaptation strategies will be required to minimize the adverse consequences of climate change in the Southwest US and in Texas, and to capitalize on potential climate-induced opportunities in the northern Great Plains of the US. This establishes a robust justification for the development of an array of flexible and cost-effective adaptation strategies to contend with these diverse ecological consequences, while accounting for the varied adaptive capacity of managers to adopt and implement them. Although a few of these strategies are currently in place, others are not, and their development may require some degree of public involvement given the enormity of the challenge. The widespread occurrence of adaptation deficits in the face of current climatic variability foreshadows major challenges that will be encountered in the development and implementation of adaptation strategies that will be needed to cope with increasing climatic variability.

\section{References}

Baker NC and Huang H. 2014. A comparative study of precipitation and evaporation between CMIP3 and CMIP5 climate model ensembles in semiarid regions. J Climate 27: 3731-49.

Balch JK, Bradley BA, D'Antonio CM, and Gomez-Dans J. 2013. Introduced annual grass increases regional fire activity across the arid western USA (1980-2009). Glob Change Biol 19: 173-83.

Bierbaum RJ, Smith B, Lee A, et al. 2013. A comprehensive review of climate adaptation in the United States: more than before, but less than needed. Mitig Adapt Strateg Glob Change 18: 361-406.

Bradley BA and Wilcove DS. 2009. When invasive plants disappear: transformative restoration possibilities in the western United States resulting from climate change. Restor Ecol 17: $715-21$.

CCSP (Climate Change Science Program). 2008. Synthesis and
Assessment Product 4.3 (SAP 4.3): the effects of climate change on agriculture, land resources, water resources, and biodiversity in the United States. Washington, DC: CCSP.

Coppock DL. 2011. Ranching and multiyear droughts in Utah: production impacts, risk perceptions, and changes in preparedness. Rangeland Ecol Manag 64: 607-18.

Craine JM, Town EG, Joern A, and Hamilton RG. 2009. Consequences of climate variability for the performance of bison in tallgrass prairie. Glob Change Biol 15: 772-79.

Dilling L and Lemos MC. 2011. Creating usable science: opportunities and constraints for climate knowledge use and their implications for science policy. Global Environ Chang 21: 680-89.

Fazey I, Gamarra JBP, Fischer J, et al. 2010. Adaptation strategies for reducing vulnerability to future environmental change. Front Ecol Environ 8: 414-22.

Hoffmann I. 2010. Climate change and the characterization, breeding and conservation of animal genetic resources. Anim Genet 41: S32-S46.

Howden SM, Crimp SJ, and Stokes CJ. 2008. Climate change and Australian livestock systems: impacts, research and policy issues. Aust J Exp Agr 48: 780-88.

IPCC (Intergovernmental Panel on Climate Change). 2013. The physical science basis: contribution of Working Group I to the Fifth Assessment Report. www.ipcc.ch/report/ar5/wg1/. Viewed 18 Mar 2015.

IPCC (Intergovernmental Panel on Climate Change). 2014. Impacts, adaptation and vulnerability: contribution of Working Group II to the Fifth Assessment Report. www.ipcc.ch/report/ar5/wg2/. Viewed 18 Mar 2015.

Johnston T. 2014. Dry age beef. Chicago, IL: Meatingplace. http://dryagebeef.meatingplace.com/index.php. Viewed 23 Jan 2015.

Joyce LA, Briske DD, Brown JR, et al. 2013. Climate change and North American rangelands: assessment of mitigation and adaptation strategies. Rangeland Ecol Manag 66: 512-28. 
Kachergis E, Derner JD, Cutts BB, et al. 2013. Increasing flexibility in rangeland management during drought. Ecosphere 5: art77.

Kates RW, Travis WR, and Wilbanks TJ. 2012. Transformational adaptation when incremental adaptations to climate change are insufficient. P Natl Acad Sci USA 109: 7156-61.

Knapp AK, Beier C, Briske DD, et al. 2008. Consequences of more extreme precipitation regimes for terrestrial ecosystems. BioScience 58: 811-21.

Liu Z, Smith Jr WJ, and Safi AS. 2014. Rancher and farmer perceptions of climate change in Nevada, USA. Climatic Change 122: 313-27.

Lubell MN, Cutts BB, Roche LM, et al. 2013. Conservation program participation and adaptive rangeland decision-making. Rangeland Ecol Manag 66: 609-20.

Marshall NA and Smajgl A. 2013. Understanding variability in adaptive capacity on rangelands. Rangeland Ecol Manag 66 : 88-94.

Marshall NA and Stokes CJ. 2014. Influencing adaptation processes on the Australian rangelands for social and ecological resilience. Ecol Soc 19: 14

Marshall NS. 2010. Understanding social resilience to climate variability in primary enterprises and industries. Global Environ Chang 20: 36-43.

Marshall NS. 2011. Assessing resource dependency on the rangelands as a measure of climate sensitivity. Soc Natur Resour 24: $1105-15$.

Meehl GA, Covey C, Delworth T, et al. 2007. The WCRP CMIP3 multi-model dataset: a new era in climate change research. $B$ Am Meteorol Soc 88: 1383-94.

Mendelsohn R. 2000. Efficient adaptation to climate change. Climatic Change 45: 583-600.

Morgan JA, Milchunas DG, LeCain DR, et al. 2007. Carbon dioxide enrichment alters plant community structure and accelerates shrub growth in the shortgrass steppe. P Natl Acad Sci USA 104: 14724-29.

Morgan JA, Moiser AR, Milchunas DG, et al. 2004. CO, enhances productivity, alters species composition, and reduces digestibility of shortgrass steppe vegetation. Ecol Appl 14: 208-19.

Mu JE, McCarl BA, and Wein AM. 2013. Adaptation to climate change: changes in farmland use and stocking rate in the US. Mitig Adapt Strateg Glob Change 18: 713-30.

NASS (National Agricultural Statistics Service). 2012a. Percent of farms with sales of less than \$10 000: 2012. Washington, DC: USDA NASS. www.agcensus.usda.gov/Publications/2012/ Online_Resources/Ag_Atlas_Maps/Economics/Farms_by_Size/ 12-M009.php. Viewed 11 Jan 2015.

NASS (National Agricultural Statistics Service). 2012b. Percent of principal farm operators 65 years old and over: 2012. Washington, DC: USDA NASS. www.agcensus.usda.gov/ Publications/2012/Online_Resources/Ag_Atlas_Maps/Operators/ Characteristics/12-M124.php. Viewed 11 Jan 2015.

NASS (National Agricultural Statistics Service). 2012c. Percent of principal farm operators reporting primary occupation as farming: 2012. Washington, DC: USDA NASS. www. agcensus.usda.gov/Publications/2012/Online_Resources/Ag_ Atlas_Maps/Operators/Principle_Occupation/12-M120.php. Viewed 11 Jan 2015.

NRC (National Research Council). 2010. Adapting to climate change. Washington, DC: National Academy Press.

Polley HW, Briske DD, Morgan JA, et al. 2013. Climate change and North American rangelands: evidence, trends, and implications. Rangeland Ecol Manag 66: 493-511.
Reimer A and Prokopy L. 2014. One federal policy, four different policy contexts: an examination of agri-environmental policy implementation in the midwestern United States. Land Use Policy 38: 605-14.

Reynolds JF, Stafford Smith DM, Lambin EF, et al. 2007. Global desertification: building a science for drylands. Science 316 : 847-51.

Sayre NF, McAllister RRJ, Bestelmeyer BT, et al. 2013. Earth Stewardship of rangelands: coping with ecological, economic, and political marginality. Front Ecol Environ 11: 348-54.

Schauer CS, Bohnert DW, Ganskopp DC, et al. 2005. Influence of protein supplementation frequency on cows consuming lowquality forage: performance, grazing behavior, and variation in supplement intake. J Anim Sci 83: 1715-25.

Smith SD, Huxman TE, Zitzer SF, et al. 2000. Elevated $\mathrm{CO}_{2}$ increases productivity and invasive species success in an arid ecosystem. Nature 408: 79-82.

Stafford Smith DM, McKeon GM, Watson IW, et al. 2007. Learning from episodes of degradation and recovery in variable Australian rangelands. P Natl Acad Sci USA 104: 20690-95.

Taylor KE, Stouffer RJ, and Meehl GA. 2012. An overview of CMIP5 and the experiment design. B Am Meteorol Soc 93: 485-98.

Torell LA, Murugan S, and Ramirez OA. 2010. Economics of flexible versus conservative stocking strategies to manage climate variability risk. Rangeland Ecol Manag 63: 415-25.

Twidwell D, Rogers WE, Fuhlendorf SD, et al. 2013. The rising Great Plains fire campaign: citizens' response to woody plant encroachment. Front Ecol Environ 11: e64-e71; doi:10.1890/130015.

USGCRP (US Global Change Research Project). 2009. Global climate change impacts in the United States. In: Karl TR, Melillo JM, and Peterson TC (Eds). Cambridge, UK: Cambridge University Press.

Volder A, Briske DD, and Tjoelker MG. 2013. Climate warming and precipitation redistribution modify tree-grass interactions and tree species establishment in a warm-temperate savanna. Glob Change Biol 19: 843-57.

Walther GR. 2003. Plants in a warmer world. Perspect Plant Ecol 6/3: 169-85.

Williamson T, Hesseln H, and Johnston M. 2012. Adaptive capacity deficits and adaptive capacity of economic systems in climate change vulnerability assessment. Forest Policy Econ 15: 160-66.

Zhang YW, Hagerman AD, and McCarl BA. 2013. Influence of climate factors on spatial distribution of Texas cattle breeds. Climatic Change 118: 183-95.

Ziska LH, Reeves JB, and Blank B. 2005. The impact of recent increases in atmospheric $\mathrm{CO}_{2}$ on biomass production and vegetative retention of cheatgrass (Bromus tectorum): implications for fire disturbance. Glob Change Biol 11: 1325-32.

${ }^{4}$ US Department of Agriculture, Jornada Experimental Range, Natural Resource Conservation Service, New Mexico State University, Las Cruces, NM; ${ }^{5}$ University of Colorado and National Oceanic and Atmospheric Administration, Earth Systems Research Laboratory, Boulder, CO; ${ }^{6}$ US Department of AgricultureAgricultural Research Service, Crops Research Laboratory, Fort Collins, CO; ${ }^{7}$ Department of Agricultural Economics, Texas AEM University, College Station, TX; ${ }^{8}$ Animal and Range Sciences Department, New Mexico State University, Las Cruces, NM 